\title{
Awareness towards signs and symptoms of stroke and assessment of factors associated with knowledge of five symptoms of stroke among general public Malaysia: A regression analysis.
}

Abdullah Abdulmajid Abdo Ahmed Albohari ( $\square$ abdullahalbohari@gmail.com )

Universiti Sains Malaysia - Kampus Kesihatan https://orcid.org/0000-0002-1524-3297

Abdulkareem Mohammed AL-Shami

International Islamic University Malaysia Kulliyyah of Pharmacy

Abdul Rahman Fata Nahas

International Islamic University Malaysia Kulliyyah of Pharmacy

Adeel Aslam

International Islamic University Malaysia Kulliyyah of Pharmacy

Mohammed Zawiah

Universiti Sains Malaysia - Kampus Kesihatan

Shazia Jamshed

International Islamic University Malaysia Kulliyyah of Pharmacy

Research article

Keywords: Appropriate action, Awareness, Malaysia, Signs, Stroke, Symptoms,

Posted Date: March 18th, 2020

DOI: https://doi.org/10.21203/rs.3.rs-17583/v1

License: (c) (i) This work is licensed under a Creative Commons Attribution 4.0 International License.

Read Full License 


\section{Abstract}

Background Stroke remains one of the leading cause of mortality and disability in developing and developed countries. Lack of awareness towards signs and symptoms of stroke leads to delayed presentation to the hospital contributing towards increased morbidity and mortality. This study aimed to assess the awareness of and action towards signs and symptoms of stroke.

Methodology This is cross-sectional study executed among 393 lay public who aged 18-64 years old in Kuantan, Pahang, Malaysia using structured questionnaire survey.

Results Mojority of respondents (78) identifed sudden face, arms and leg numbness whereas $42 \%$ of them identifed problems in vision. However, $10.4 \%$ were unaaware of any symptoms while $30 \%$ identified appropriate action. Furthermore, $88.8 \%$ recognized at least one stroke symptoms and $27.5 \%$ of them identifed all five stroke symptoms as well as $9.4 \%$ of individuals had excellent awareness (aware of all five stroke symptoms and appropriate action "calling an ambulance"). Multivariable logistic regression shows that individuals aged $18-45$ years $(\mathrm{OR}=0.054,95 \% \mathrm{Cl}=0.006-0.500, \mathrm{p}=0.010)$, self-employed $(\mathrm{OR}=12.430,95 \% \mathrm{Cl}=1.372-31.908, \mathrm{p}=0.028)$, those who were diagnosed with hypertension $(\mathrm{OR}=0.129$, $95 \% \mathrm{Cl}=0.025-0.673, \mathrm{p}=0.015)$ and student $(\mathrm{OR}=35.945 .95 \% \mathrm{Cl}=1.745-740.615, \mathrm{p}=0.020)$ were more likely to recognise all the five stroke symptoms and appropriate action.

Conclusion The awareness and action towards signs, symptoms is poor among lay public in Kuantan, Malaysia. Therefore, the findings of this study would be a baseline for program interventions that focus on public awareness and policy development on stroke management.

\section{Background}

Stroke is considered as the third major cause of mortality globally and one of the leading causes of morbidity in the developed countries [1-3]. Around 14 million individuals suffered from stroke in the firsttime globally [4]. In 2015, the mortality rate by stroke accounted for $11.8 \%$ of all deaths worldwide [5]. Annually, 6.2 million stroke deaths are reported, taking a life each five seconds [4]. In Malaysia, stroke remined the one of the top five principal causes of the fatalities and one of the top 10 diseases that leads to hospitalization [6]. stroke has been also among the major five highest burden diseases, based on disability-adjusted life years.

Thrombolysis has been shown to be an effective treatment of acute ischemic stroke during the four and half hours following ischemic stroke. It also shows improvement in the clinical outcomes of the patients $[7,8]$. Regardless of daily activities, the aforementioned medical intervention can reduce death and physical dependence [8]. Studies have reported that most stroke patients arrived at the emergency medical care were brought lately [9-11], this could be attributed to the delay in the decision of seeking medical treatment after the appearance of stroke symptoms [12]. Pre-hospital delay may also happen because patients do not activate emergency medical service, but rather directly access emergency department, contact first a family member or the family doctor [13-15]. 
Several studies revealed lack of knowledge towards warning signs and symptoms of stroke [14-19] and its risk factors, as well as the common behavior of procrastination culture, which leads to delay in presentation to the hospital. Awareness towards signs and symptoms of stroke might lead to spontaneous admission to the hospital for the first time of onset [20], this in turn will reduce the time for hospital admission, which might increase the number of eligibility of patients intervention by thrombolysis [20]. There are limited studies carried out among Malaysian inpatients and outpatients [2123]. To the best of our knowledge, there are no studies being reported from lay public in Malaysia. Therefore, the aim of this study to assess the the awareness towards signs and symptoms of stroke among the lay public in Kuantan, Pahang, Malaysia.

\section{Methods}

\section{Study design and site}

A cross-sectional study was performed among the lay public who aged 18-64 years old in Kuantan, Pahang, Malaysia. Healthcare professionals in clincal seting and academic settings as well as those who are studying medicine, pharmacy, nursing were all exempted. A sample size of 393 was calculated, and to be collected in Kuantan, Pahang, Malaysia.

\section{Study Instrument and Data Collection}

The questionnaire used in this study was developed and translated to Bahasa Malaya by Ahmed et al. 2019 [24]. Data were collected from participants through a structured questionnaire by two priorly trained data collectors using face to face interview. The survey included sociodemographic characteristics (age, sex, marital status, nationality, race, level of education, family status, monthly income, as well as the history of family and social habits). For awareness about stroke symptoms, the participants were asked if any of the following is a known stroke symptom; sudden confusion, trouble speaking or understanding speech, sudden numbness or weakness of the face, arm or leg (especially on one side of the body), sudden trouble seeing in one or both eyes, sudden difficulty walking, dizziness, loss of balance or coordination and sudden severe headache with no known cause. Participants who answered "yes" to all the symptoms of stroke were considered as having awareness about stroke. However, those who answered "no" or "I don't know" to the symptoms were considered as having no awareness about stroke symptoms. Some symptoms which are incorrect and not related to strokes such as sudden nose bleeding, sudden vomiting, and high temperature were also included to assess and account for the possibility that the participant would answer "yes" to all symptoms. To assess the awareness of action towards symptoms of stroke, the respondents were asked: "if you see someone showing signs and symptoms of stroke, what do you think you should do first?" Respondents were asked to select from the list of actions that included: give them aspirin; take them to hospital or clinic; call an ambulance; call the police; contact their family; or other actions. In the analysis of this study, respondents who correctly 
answered all five symptoms with the response "yes," incorrect symptoms with the response "no" and appropriate action (call an ambulance) were defined as having all recommended stroke knowledge.

\section{Ethical Approval}

The ethical approval for this study was received from the Ethical Committee on $8^{\text {th }}$ March 2018 and IIUM Research Ethics Committee (IREC132) on 30 ${ }^{\text {th }}$ April 2018.

\section{Data Analysis}

Descriptive and comparative statistical analysis was performed using SPSS version 23. Chi-square, Mann-Whitney $\mathrm{U}$, and Kruskal-Wallis tests were used. A multivariable logistic regression analysis was run to identify predictive factors among sociodemographics on the awareness of all five stroke symptoms.

\section{Results}

\section{Sociodemographic characteristics}

The sample (N=393) included 204 (51.9\%) males and 189 (48.1\%) females residing in Kuantan city that is located on the east coast of Malaysia. Table 1 shows that the highest number of respondents $(n=122$, $31 \%$ ) was from the lowest age group (18-25 years old). This was followed by the age group (56-64) and (26-35) years old, represented by $20.1 \%$ and $19.8 \%$, respectively. In addition, $53.7 \%$ of the respondents were married, followed by $44.3 \%$ single respondents. Furthermore, the majority of the participants $(52.2 \%)$ had high school education. This was followed by $28 \%$ of participants comprising undergraduate students. Moreover, the highest number $(n=200,50.9 \%)$, followed by $66(16.5 \%)$ students' participants. According to the race, the participants were divided into four groups. The majority of the participants $(n=213,54.2 \%)$ were Malay, followed by $30.3 \%$ Chinese and $15.6 \%$ Indians. Likewise, the majority $(68.4 \%)$ of the respondents had a monthly income of less than 500 USD followed by $20.6 \%$ with monthly incomes between 500 and 1000 USD. Furthermore, about $17 \%$ of the respondents have been diagnosed with hypertension, $12 \%$ with diabetes, and $15 \%$ with hypercholesteremia. On the other hand, about $3.8 \%$ of respondents had heart disease, $1.8 \%$ had a stroke, and $1 \%$ of the respondents had other diseases like gout. <Table 1>

\section{Awareness and action towards signs and symptoms of stroke}

Table 2 shows that the majority of participants $(78.8 \%)$ recognized sudden numbness or weakness of the face, arms, and leg as a symptom of stroke (SOS). About $74.7 \%$ of the respondents identified sudden 
trouble walking, dizziness, loss of balance as SOS while $68.05 \%$ of participants reported sudden confusion trouble speaking or understanding speech. Furthermore, $57.5 \%$ of participants recognized severe headache with no known cause as SOS. Only $42.1 \%$ indicated sudden troubling seeing with one or both eyes as SOS. Additionally, 7.9\% of respondents answered "Yes" to all five SOS and three trap questions while $2.5 \%$ of participants answered "No" to all SOS and trap questions. This implies that $10.4 \%$ of all the respondents did not have an awareness of SOS. Approximately $29.8 \%$ of the participants recognized "call an ambulance" as appropriate action if someone is suffering from stroke symptoms. According to the differences in the awareness of SOS in relation to sociodemographics, the MeanWhitney $\mathrm{U}$ test showed that females were more likely to recognize sudden confusion, trouble speaking or understanding speech $(U=16606, p=0.003)$, sudden numbness or weakness of face, arm or leg $(U=17628$, $p=0.039)$, and sudden trouble walking dizziness, loss of balance ( $\mathrm{U}=17491, p=0.035)$ than males. The Kruskal-Wallis (KW) test also showed that those who were aged 36-45 years old had more awareness of sudden confusion, trouble speaking $\left(x^{2}=20.470, p=0.000\right)$ and sudden trouble walking dizziness, loss of balance $\left(x^{2}=14.399, p=0.006\right)$ than other age groups.

Furthermore, widows showed greater awareness of sudden confusion, trouble speaking than others $\left(x^{2}=13.790, p=0.003\right)$ than other marital statuses. The KW test also displayed that the Chinese participants had more awareness than other races on sudden confusion, trouble speaking $\left(x^{2}=12.164\right.$, $p=0.007)$. Both the Chinese and Malay participants demonstrated greater awareness of sudden numbness or weakness of the face, arm and sudden trouble seeing than Indians and others $\left(x^{2}=17.089\right.$, $p=0.001)$ and $\left(x^{2}=10.161, p=0.017\right)$, respectively. Moreover, respondents with postgraduate level of education demonstrated more awareness of sudden confusion, trouble speaking, numbness or weakness of the face, arms, leg and sudden trouble walking, dizziness than other education levels $\left(x^{2}=20.331\right.$, $p=0.002),\left(x^{2}=14.378, p=0.026\right)$ and $\left(x^{2}=12.600, p=0.049\right)$ respectively. In addition, respondents who earned more than RM6000 monthly income showed higher awareness on sudden confusion, trouble speaking, and sudden numbness or weakness of the face, arms or leg than others $\left(x^{2}=19.169, p=0.000\right)$ and $\left(x^{2}=11.140, p=0.011\right)$, respectively. The Mann-Whitney test also demonstrated that participants who received information of stroke and heart disease through public service advertisements or the internet as well as those who heard about heart attack and stroke showed better awareness of sudden trouble seeing with one or both eyes and sudden severe headache than those who did not receive any information $(\mathrm{U}=12725, p=0.009)$ and $(\mathrm{U}=11745, p=0.000)$, respectively.

Additionally, those who were aware that stroke needs an urgent treatment were more likely to recognize sudden confusion, trouble in speaking, sudden numbness or weakness in the face, arms or leg, sudden trouble seeing with one or both eyes, sudden trouble walking dizziness and sudden severe headache than others who were unaware $(U=2729, p=0.001),(U=2807, p=0.000),(U=2570, p=0.001),(U=2629, p=0.000)$, and $(\mathrm{U}=2476, \mathrm{p}=0.000)$, respectively. <Table 2> 


\section{Awareness of stroke symptoms based on the number of recognized stroke symptoms}

Table 3 shows that the majority of the respondents (88.8\%) recognized at least one SOS. However, only $27.5 \%$ of the respondents were aware of all five SOS while only $3.3 \%$ had an excellent awareness of all five SOS. Respondents who answered "Yes" to the five symptoms of stroke were categorized as being aware of symptoms. Only respondents who answered "No" to the trap questions, however, were considered as being aware of stroke symptoms because the trap questions are not a stroke symptom in reality.

Furthermore, $9.4 \%$ of participants had an excellent awareness of all five stroke symptoms and appropriate action (calling an ambulance). With regards to the association between sociodemographics and awareness of all five SOS, the KW test showed that participants aged between 46-55 years had more awareness of all five stroke symptoms than other age groups $\left(x^{2}=16.028, p=0.003\right)$. In addition, married participants had a better awareness of all five SOS than other marital statuses $\left(x^{2}=16.005, p=0.001\right)$. However, there were no significant differences between different races on all five SOS $\left(x^{2}=6.863\right.$, $p=0.076)$, different levels of education $\left(x^{2}=9.647, p=0.140\right)$ as well as monthly income $\left(x^{2}=5.007\right.$, $p=0.171)$.

There were significant differences, however, between employment status and all five SOS. Respondents who were self-employed and housewives demonstrated greater awareness of all five SOS than others $\left(x^{2}=16.310, p=0.006\right)$. Likewise, the Mann-Whitney test showed that participants who had a family history of stroke and received information related to stroke and heart disease demonstrated more awareness of all five SOS than others without any family history of stroke and did not receive any information $(U=16927, p=0.014)$ and $(U=12320, p=0.001)$, respectively. Nevertheless, no significant differences were found between participants who had risk factors of stroke, heart disease, and all five SOS. <Table 3>

\section{Assessment of the factors affecting awareness of all five stroke symptoms and appropriate action}

Multivariable logistic regression revealed three factors that showed a strong association with excellent awareness of all five stroke symptoms and appropriate action. Age has a significant association with excellent awareness. Respondents aged 18-45 years had greater awareness than those whose ages were 46-64 years old. In other words, respondents aged 18-25 years were 0.054 more likely to have an excellent awareness than those aged $46-64$ years $(\mathrm{OR}=0.054,95 \% \mathrm{Cl}=0.006-0.500, p=0.010)$. In addition, selfemployed as well as student participants had a greater excellent awareness of all five stroke symptoms than housewives, unemployed, and retired respondents. In other words, self-employed respondents were 12.430 times more likely to have an excellent awareness of all five stroke symptoms and appropriate action than retired participants $(\mathrm{OR}=12.430,95 \% \mathrm{Cl}=1.372-31.908, p=0.028)$. Similarly, students were 
35.945 times more likely to be aware of all five stroke symptoms and appropriate action than those who were retired $(\mathrm{OR}=35.945 .95 \% \mathrm{Cl}=1.745-740.615, p=0.020)$.

Furthermore, respondents who had been diagnosed with hypertension were 0.129 times more likely to be aware of all five stroke symptoms and appropriate action than those without hypertension $(\mathrm{OR}=0.129$, $95 \% \mathrm{Cl}=0.025-0.673, p=0.015)$. On the other hand, there was no significant difference between those who had heard about stroke and those who did not hear, as shown in Table 4. <Table 4>

\section{Discussion}

This is the first study conducted among the lay public in Kuantan, Pahang, Malaysia to assess the awareness and action towards signs and symptoms of stroke and its risk factors. Our findings reported that majority were not aware that stroke requires prompt treatment whenever someone is experiencing the symptoms. Only fewer participants were mindful of the appropriate action of calling an ambulance, due to the lack of knowledge about calling an ambulance. In general, majority did not identify all stroke symptoms. Nevertheless, most respondents knew at least one sign. This is in agreement with studies performed in Australia and the US $([17,25]$ wherein the majority recognized at least one symptom. Likewise, a study from Singapore demonstrated that most of the respondents identified one symptom of stroke $[26,27]$.

In the current study, however, majority expressed their unawareness of all the symptoms of a stroke. In other words, only a few proportion of respondents were aware of all stroke symptoms. Sudden numbness or weakness of the face, arm or leg was the most commonly recognized stroke symptom in this study. This is in agreement with studies in Spain, the US, and Singapore where the most frequent stroke symptom recognised was numbness or weakness of the face, arm or leg [27-29]. On the contrary, an Australian study reported paralysis or partial weakness as the lowest recognised symptom of stroke [25]. In addition, the most common symptom recognised by the respondents was numbness or weakness of the face, arm or leg, followed by the immediate change in gait, sudden confusion, and difficulty in speaking. The results are in accordance with the studies in Nigeria, Singapore and China [27, 30-32].

Regarding sudden vision changes, the findings from our study are in line with the studies in Nigeria [30] and Ireland [33]. The Australian study, however, reported sudden vision changes as the most recognized symptom of stroke [25]. The disparity between our results and the reported results may be due to the sources of information in the two countries. In Australia, for instance, the most common sources of information were general life experiences and personal acquaintances, whereas, in the current research the most common sources of information were TV, the internet, and social media [25]. Furthermore, in this study, there were no significant differences between males and females which is in concordance with a large body of literature $([32,33]$.

In terms of awareness of stroke symptoms for many symptoms, majority recognized at least one stroke symptom, which is in line with a Spanish study which reported that nearly three-fourths of their respondents identified at least one symptom [29]. Furthermore, most of the respondents recognised at 
least two stroke symptoms. This is comparable with a study carried out in Ireland, which reported that many respondents identified two symptoms of a stroke [33]. Moreover, the present study showed that nearly three-fourth of the respondents were able to identify three symptoms of a stroke. These are in line with a study in France which reported that $63 \%$ of the participants were able to identify three symptoms of a stroke [34]. The proportion of people who knew either two or three symptoms was higher in this study compared to a study in Australia which reported a smaller percentage of respondents who recognized two or three symptoms [25]. In the current study, only one-third of the respondents identified all five stroke symptoms and 3.3\% identified five stroke symptoms as well as three non-symptoms of stroke. These findings are consistent with a study performed in China, where $15.6 \%$ of respondents recognised five stroke symptoms and $2.5 \%$ reported only two non-stroke symptoms [32].

Regarding an appropriate action when someone is having stroke symptoms, our findings showed poor awareness, although many participants had a high school qualification. Some reported that "taking patients to hospital" is the appropriate action, while others favoured to give aspirin. This result was slightly different from a study conducted in Brazil, which reported that half of the participants were aware of dialling ambulance when someone is suspected of stroke and $34.6 \%$ of respondents recognized the number of an ambulance [35]. Basically, the level of education could be responsible for the differences. In the current study, the majority of participants among the lay public in Kuantan had a high school of education as compared to Brazilian study participants with a higher level of education. On the contrary, a study performed in the US reported that a high percentage of respondents recognised calling ' 911 ' as suitable action when someone is having a stroke [36]. The reasons for the differences between our study and the previous study could be related to the difference in participants' sociodemographics, as in the US study the participants reported to be at high-risk of stroke or had a stroke previously, while the current study was conducted among the lay public. Similarly, a study was carried out in India reported that $71.1 \%$ indicated to send the victim to a hospital, while less than half indicated to call a doctor [37].

Moreover, the findings from our study showed that education levels were not associated with appropriate action of calling an ambulance or going to the hospital emergency department as first aid for stroke signs and symptoms. This is in line with a study in Australia [25]. In contrast, a study in China reported that education levels were related to appropriate action towards calling an ambulance [32].

The current research showed that education level is related to high awareness of stroke symptoms and risk factors. These findings are in line with the literature $[18,19,25,35,37-48]$ and high risk factors groups [49]. We also found that hypertensive patients showed better awareness of stroke symptoms. The results were in agreement with studies done in the US and Australia which reported that patients with high blood pressure demonstrated better awareness of stroke risk factors SRF and stroke symptoms [18, $19,25,50]$. Our study also reported that a higher level of education is a significant predictor of greater awareness of signs and symptoms of stroke in agreement with studies in Australia and the US [17, 25].

The awareness towards signs and symptoms of stroke in this research were insufficient for the first-time hospital attendants. Most of the lay public in this study recognized only the common signs and 
symptoms, whereas most did not know the appropriate action towards signs and symptoms of a stroke. A few numbers identified all five SOS leading towards appropriate action (calling an ambulance). These findings reflect that the public awareness regarding their knowledge of stroke diseases is low. In addition, this lack of awareness towards signs and symptoms of stroke shows an existence of gap in public awareness regardless of their age, marital status or level of education. Therefore, awareness campaign intervention is urgently needed in Malaysia to raise the awareness of stroke, which could reduce death cases due to stroke. As a study in Australia reported that public awareness campaign intervention has a significant impact to reduce the mortality rate due to stroke [51].

\section{Conclusions}

The awareness of stroke symptoms, risk factors, and appropriate action was found to be poor in Kuantan, Pahang, Malaysia. Most participants recognized only one or two signs and symptoms of stroke which were only the common signs and symptoms of a stroke. However, less than one-fourth reported unawareness of even one single symptom while the highest number of respondents identified one or two modifiable SRF. Furthermore, a fewer number of participants identified diabetes as a risk factor of stroke.

The findings of the present research address the need to initiate 'Malaysia Awareness Campaign for STROKE' (MAC-STROKE) to augment the knowledge of all modifiable risk factors of stroke among lay public. Mass media campaigns and awareness programs in educational institutions for the lay public especially youths and distribution of informational leaflets to high-risk individuals are recommended as future strategies.

\section{Declarations}

\section{Abbreviations}

MAC-STROKE: Malaysia Awareness Campaign for STROKE; SOS: Symptoms of stroke; KW: Kruskal Willis Test.

\section{Acknowledgements}

The authors would like to thank all participants who participate in this research.

\section{Authors' contributions}

This research is a part of AAAA Master's degree. It was conducted by AAAA and supervised by AKMA, SJ. Ethical approval of this research was obtained by AAAA, AKMA and SJ. Statistical analysis, writing original draft of manuscript, were done by AAAA, AKMA, SJ, MZ, ARF, and AA. All authors read and approved the final manuscript. 


\section{Funding}

None

\section{Availability of data and materials}

The data of this research is part of larger data of a master's degree project. The data is available upon request

\section{Ethics approval and consent to participate}

This research has been approved by International Islamic University Malaysia Research Ethics Committee (IREC 2018-132). Prior to participate in the study, all participants provided a written informed consent after the study was fully explained to them.

\section{Consent for publication}

Not applicable.

\section{Competing interests}

Dr. Shazia Jamshed is an associate editor in the BMC Public Health

\section{Author details}

${ }^{1}$ Department of Pharmacy Practice, International Islamic University Malaysia, Kuantan, Pahang, Malaysia. ${ }^{2}$ Discipline of clinical pharmacy, School of pharmaceutical sciences, University Sains Malaysia, Penang, Malaysia.

\section{References}

1. Flynn D, Ford GA, Rodgers H, Price C, Steen N, Thomson RG: A time series evaluation of the FAST National Stroke Awareness Campaign in England. PLoS One 2014, 9(8):e104289.

2. Droste DW, Safo J, Metz RJ, Osada N: Stroke awareness in luxemburg: deficit concerning symptoms and risk factors. Clinical Medicine Insights: Cardiology 2014, 8:CMC. S15225.

3. Nakibuuka J, Sajatovic M, Katabira E, Ddumba E, Byakika-Tusiime J, Furlan AJ: Knowledge and perception of stroke: a population-based survey in Uganda. ISRN stroke 2014, 2014.

4. The top 10 causes of death [https://www.who.int/news-room/fact-sheets/detail/the-top-10-causesof-death]

5. Association AH: Heart Disease and Stroke Statistics 2018 At-a-Glance. on-line at: http://www heart org/idc/groups/ahamahpublic/@wcm/@sop/@smd/documents/downloadable/ucm_491265 pdf 2018. 
6. Loo KW, Gan SH: Burden of stroke in Malaysia. Int J Stroke 2012, 7(2):165-167.

7. Hacke W, Kaste M, Bluhmki E, Brozman M, Dávalos A, Guidetti D, Larrue V, Lees KR, Medeghri Z, Machnig T: Thrombolysis with alteplase 3 to 4.5 hours after acute ischemic stroke. N Engl J Med 2008, 359(13):1317-1329.

8. TSIVQOULIS G, VALEXANDROV A, LEES KR, WAHLGREN N, AHMED N: Thrombolysis with alteplase 3$4.5 \mathrm{~h}$ after acute ischaemic stroke (SITS-ISTR): an observational study. Commentary. Lancet (British edition) 2008, 372(9646).

9. Chang K-C, Tseng M-C, Tan T-Y: Prehospital delay after acute stroke in Kaohsiung, Taiwan. Stroke 2004, 35(3):700-704.

10. Salisbury H, Banks B, Footitt D, Winner S, Reynolds D: Delay in presentation of patients with acute stroke to hospital in Oxford. QJM: monthly journal of the Association of Physicians 1998, 91(9):635640.

11. Johnston F, Wardlaw J, Dennis M, Lewis S, Nimmo G, Lindley R, Warlow C: Delays in stroke referrals. The Lancet 1999, 354(9172):47-48.

12. Keskin Ö, Kalemoğlu M, Ulusoy RE: A clinic investigation into prehospital and emergency department delays in acute stroke care. Med Princ Pract 2005, 14(6):408-412.

13. Wein TH, Staub L, Felberg R, Hickenbottom SL, Chan W, Grotta JC, Demchuk AM, Groff J, Bartholomew LK, Morgenstern LB: Activation of emergency medical services for acute stroke in a nonurban population: the TLL Temple Foundation Stroke Project. Stroke 2000, 31(8):1925-1928.

14. Carroll C, Hobart J, Fox C, Teare L, Gibson J: Stroke in Devon: knowledge was good, but action was poor. J Neurol Neurosurg Psychiatry 2004, 75(4):567-571.

15. Lecouturier J, Murtagh MJ, Thomson RG, Ford GA, White M, Eccles M, Rodgers H: Response to symptoms of stroke in the UK: a systematic review. BMC Health Serv Res 2010, 10(1):157.

16. Jones SP, Jenkinson AJ, Leathley MJ, Watkins CL: Stroke knowledge and awareness: an integrative review of the evidence. Age Ageing 2010, 39(1):11-22.

17. Pancioli AM, Broderick J, Kothari R, Brott T, Tuchfarber A, Miller R, Khoury J, Jauch E: Public perception of stroke warning signs and knowledge of potential risk factors. Jama 1998, 279(16):1288-1292.

18. Reeves MJ, Hogan JG, Rafferty AP: Knowledge of stroke risk factors and warning signs among Michigan adults. Neurology 2002, 59(10):1547-1552.

19. Schneider AT, Pancioli AM, Khoury JC, Rademacher E, Tuchfarber A, Miller R, Woo D, Kissela B, Broderick JP: Trends in community knowledge of the warning signs and risk factors for stroke. Jama 2003, 289(3):343-346.

20. Stroebele N, Mueller-Riemenschneider F, Nolte CH, Mueller-Nordhorn J, Bockelbrink A, Willich SN:

Knowledge of risk factors, and warning signs of stroke: a systematic review from a gender perspective. Int J Stroke 2011, 6(1):60-66. 
21. Sowtali SN, Harith S, Mohamed M, Yusoff DM: Stroke knowledge level among stroke patients admitted to hospital Raja Perempuan Zainab II, Kelantan, Malaysia. J Exp Stroke Trans/ Med 2016, 9(1):1-11.

22. Sowtali SN, Yusoff DM, Harith S, Mohamed M: Comparison of knowledge, attitude and practice on stroke knowledge in Malaysia and other nations: a review of literature. Int Med J 2017, 24(2):168173.

23. Ching S, Chia YC, Chew BN, Soo MJ, Lim HM, Sulaiman WAW, Hoo FK, Saw ML, Ishak A, Palanivelu $\mathrm{T}$ : Knowledge on the action to be taken and recognition of symptoms of stroke in a community: findings from the May Measurement Month 2017 blood pressure screening Programme in Malaysia. BMC Public Health 2019, 19(1):1602.

24. Ahmed AAA, AL-Shami AM, Jamshed S, Nahas ARF: Development of questionnaire on awareness and action towards symptoms and risk factors of heart attack and stroke among a Malaysian population. BMC public health 2019, 19(1):1300.

25. Sug Yoon S, Heller RF, Levi C, Wiggers J, Fitzgerald PE: Knowledge of stroke risk factors, warning symptoms, and treatment among an Australian urban population. Stroke 2001, 32(8):1926-1930.

26. Control CfD, (CDC) P: Awareness of stroke warning signs-17 states and the US Virgin Islands, 2001. MMWR Morbidity and mortality weekly report 2004, 53(17):359.

27. Quah JLJ, Yap S, Cheah SO, Ng YY, Goh ES, Doctor N, Leong BS-H, Tiah L, Chia MYC, Ong MEH: Knowledge of signs and symptoms of heart attack and stroke among Singapore residents. BioMed research international 2014, 2014.

28. Control CfD, Prevention: Awareness of stroke warning signs-17 states and the US Virgin Islands, 2001. MMWR Morbidity and mortality weekly report 2004, 53(17):359.

29. Ramírez-Moreno JM, Alonso-González R, Peral-Pacheco D, Millán-Núñez MV, Aguirre-Sánchez JJ: Stroke awareness is worse among the old and poorly educated: a population-based survey. Journal of Stroke and Cerebrovascular Diseases 2015, 24(5):1038-1046.

30. Arisegi SA, Awosan KJ, Oche MO, Sabir AA, Ibrahim MT: Knowledge and practices related to stroke prevention among hypertensive and diabetic patients attending Specialist Hospital, Sokoto, Nigeria. Pan African Medical Journal 2018, 29(1):1-17.

31. Obembe AO, Olaogun MO, Bamikole AA, Komolafe MA, Odetunde MO: Awareness of risk factors and warning signs of stroke in a Nigeria university. Journal of Stroke and Cerebrovascular Diseases 2014, 23(4):749-758.

32. Yang J, Zheng M, Cheng S, Ou S, Zhang J, Wang N, Cao Y, Wang J: Knowledge of stroke symptoms and treatment among community residents in Western Urban China. Journal of Stroke and Cerebrovascular Diseases 2014, 23(5):1216-1224.

33. Hickey A, Holly D, McGee H, Conroy R, Shelley E: Knowledge of stroke risk factors and warning signs in Ireland: development and application of the Stroke Awareness Questionnaire (SAQ). Int J Stroke 2012, 7(4):298-306. 
34. Neau J-P, Ingrand P, Godeneche G: Awareness within the French population concerning stroke signs, symptoms, and risk factors. Clinical neurology and neurosurgery 2009, 111(8):659-664.

35. Pontes-Neto OvM, Silva GS, Feitosa MR, De Figueiredo NL, Fiorot Jr JA, Rocha TN, Massaro AR, Leite JP: Stroke awareness in Brazil: alarming results in a community-based study. Stroke 2008, 39(2):292-296.

36. Ellis C, Egede LE: Stroke recognition among individuals with stroke risk factors. The American journal of the medical sciences 2009, 337(1):5-10.

37. Pandian JD, Jaison A, Deepak SS, Kalra G, Shamsher S, Lincoln DJ, Abraham G: Public awareness of warning symptoms, risk factors, and treatment of stroke in northwest India. Stroke 2005, 36(3):644648.

38. Alkadry MG, Wilson C, Nicholas D: Stroke awareness among rural residents: the case of West Virginia. Soc Work Health Care 2006, 42(2):73-92.

39. Becker KJ, Fruin MS, Gooding TD, Tirschwell DL, Love PJ, Mankowski TM: Community-based education improves stroke knowledge. Cerebrovascular Diseases 2001, 11(1):34-43.

40. Falavigna A, Teles AR, Vedana VM, Kleber FD, Mosena G, Velho MC, Mazzocchin T, Silva RCd, Lucena LF, Santin JT: Awareness of stroke risk factors and warning signs in southern Brazil. Arq Neuropsiquiatr 2009, 67(4):1076-1081.

41. Góngora-Rivera F, Gutiérrez-Jiménez E, Zenteno MA, Investigators G: Knowledge of ischemic stroke among a Mexico City population. Journal of Stroke and Cerebrovascular Diseases 2009, 18(3):208213.

42. Gutiérrez-Jiménez E, Góngora-Rivera F, Martínez HR, Escamilla-Garza JM, Villarreal HJ: Knowledge of ischemic stroke risk factors and warning signs after a health education program by medical students. Stroke 2011, 42(4):897-901.

43. Kamran S, Bener A, Deleu D, Khoja W, Jumma M, Al Shubali A, Inshashi J, Sharouqi I, Al Khabouri J: The level of awareness of stroke risk factors and symptoms in the Gulf Cooperation Council countries: Gulf Cooperation Council stroke awareness study. Neuroepidemiology 2007, 29(3-4):235242.

44. Nedeltchev K, Fischer U, Arnold M, Kappeler L, Mattle HP: Low awareness of transient ischemic attacks and risk factors of stroke in a Swiss urban community. $J$ Neurol 2007, 254(2):179-184.

45. Nicol MB, Thrift AG: Knowledge of risk factors and warning signs of stroke. Vascular health and risk management 2005, 1(2):137.

46. Nóvak EM, Zétola VdHF, Muzzio JA, Puppi M, Carraro Júnior H, Werneck LC: Lay knowledge about stroke. Arq Neuropsiquiatr 2003, 61(3B):772-776.

47. Oró M, Sanahuja-Montesinos J, Hernández L, Setó E, Purroy F: The extent of knowledge about strokes among the population of a rural area in the province of Lleida. Rev Neuro/ 2009, 48(10):515519.

48. Rowe AK, Frankel MR, Sanders KA: Stroke awareness among Georgia adults: epidemiology and considerations regarding measurement. South Med J 2001, 94(6):613-613. 
49. Al Shafaee MA, Ganguly SS, Al Asmi AR: Perception of stroke and knowledge of potential risk factors among Omani patients at increased risk for stroke. BMC Neurol 2006, 6(1):38.

50. Yoon SS, Heller RF, Levi C, Wiggers J: Knowledge and perception about stroke among an Australian urban population. BMC Public Health 2001, 1(1):14.

51. Nehme Z, Andrew E, Bernard S, Patsamanis H, Cameron P, Bray JE, Meredith IT, Smith K: Impact of a public awareness campaign on out-of-hospital cardiac arrest incidence and mortality rates. European heart journal 2016, 38(21):1666-1673.

\section{Tables}

Due to technical limitations, tables are only available as a download in the supplemental files section.

\section{Supplementary Files}

This is a list of supplementary files associated with this preprint. Click to download.

- Tables.docx 